\title{
Stroke and Sleep Disorders
}

\author{
Mehmet Murat Sumer* \\ Health Sciences Faculty, Atilim University, Turkey \\ *Corresponding author: Mehmet Murat Sumer, Health Sciences Faculty, Atilim University, Turkey

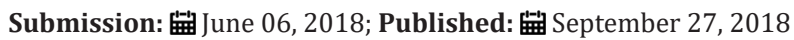

\begin{abstract}
Sleep disorders are highly prevalent in patients at risk for stroke and may be modifiable risk factors for stroke. Obstructive sleep apnea increases the risk of stroke independently, but the reported lack of therapeutic effectiveness of Continuous positive airway pressure for stroke prevention and cardiovascular protection should be cautiously interpreted. Short or long sleep duration, and insomnia with objective short sleep duration, could be risk factors for stroke and mortality. Sleep-related movement disorders, including Periodic limb movement during sleep and Restless leg syndrome are also potential risk factors for stroke. The overall findings suggest that systematic screening and proper management of sleep disturbances can substantially contribute to stroke risk modification at the population level.
\end{abstract}

\section{Introduction}

Stroke, remains one of leading causes of death and significant disability worldwide although incidence and early stroke mortality have been decreasing [1-4]. Cardinal risk factors are hypertension, cardiac disorders mainly valve disorders and atrial fibrillation, hyperlipidaemia, diabetes, smoking [5,6]. Recently, the role of sleep pathology in the development of cardiovascular and metabolic diseases has been highlightted [7-9]. Sleep, although characterized by quiescence and diminished responsiveness, is not only simple state of rest, but rather a cyclic state of periodic transitions between rapid-eye-movement (REM) and non-REM (NREM) sleep, which are precisely regulated by the central nervous system [10]. Along with the brain and other organs or physiological streams, the cardiovascular system achieves homeostatic restoration during sleep, mainly through autonomic circulatory control [11]. The decrease in blood pressure during sleep, "dipping," is a key biomarker of cardiovascular health, secondary to changes in activity and posture and also under the influence of sleep and circadian rhythms [12].

During NREM or slow wave sleep, the largest portion (up to $80 \%$ ) of normal adult sleep, the autonomic system is stabilized with vagal dominance, reduced sympathetic tone, and heightened baroreceptor gain, contributing to a significant reduction in blood pressure and heart rate, with the greatest drop occurring during NREM sleep [13,14]. REM sleep-occupying about $20 \%$ of total sleep-is dominated by marked fluctuations in sympathovagal balance (irregularly peaking sympathetic surges against a background of tonic vagal inhibition), which lead to abrupt changes in blood pressure and heart rate $[11,15]$. A compromised cardiovascular system is at risk for pathological events such as myocardial ischemia or arrhythmias during REM sleep. Sleep thus acts as a gatekeeper through cyclic oscillations between NREM and
REM sleep. Non-dipping-loss of the typical blood pressure drop during sleep-is associated with a host of poor cardiac, neurological, metabolic, and renal outcomes [16]. Sleep fragmentation causes non-dipping [17]. Non-dipping is common in older adults and is associated with an increased risk of stroke [18]. Reduced dipping is associated with brain atrophy, worse functional status, and lower daytime cerebral blood flow [19]. Common sleep disorders such as sleep apnea, insomnia, and PLMS (Periodic limb movement during sleep) activate multiple mechanisms including intermittent hypoxia-reoxygenation injury, inflammation, insulin resistance, hypothalamic-pituitary- adrenal axis activation, hemodynamic swings, cardiac arrhythmia, and hypercoagulability, all of which have the potential to provoke cardiovascular diseases [20].

Obstructive Sleep Apnea (OSA) is the most frequent sleep disorder. The prevalence of moderate-to-severe OSA in the adult general population is $4-14 \%$ and increasing with age [21,22]. Experimental and observational studies have provided evidence that OSA promotes the development of cardiovascular diseases, including stroke $[20,23]$. Moderate to severe OSA is associated with silent ischemic changes, including white matter changes and lacunae as well as cerebral microbleeds [24,25]. Carotid and intracranial atherosclerosis are also accelerated in OSA [26]. It is unclear whether continuous positive airway pressure (CPAP) has a therapeutic effect on these changes [27]. Hypertension and insulin resistance might mediate the development of stroke in OSA. Moderate-to-severe OSA is significantly associated with prevalent and incident hypertension [28]. Effective CPAP therapy, alone or in addition to antihypertensive medication, significantly reduces blood pressure [29,30]. OSA may also increase the risk for development of type 2 diabetes by mechanisms such as increased insulin resistance and high cortisol secretion [31]. Concomitant obesity might have 
a stronger effect than OSA, not mitigated by CPAP therapy. OSA is also associated with the risk for cardio embolism. People with OSA have four times the odds of atrial fibrillation [32]. Nocturnal oxygen desaturation is an independent risk factor for new onset atrial fibrillation [33].

Sleep apnea is associated with inflammation, endothelial dysfunction, hypercoagulability, and cerebral hemodynamic changes [34-41]. Recent studies reported that OSA was significantly associated with incident stroke [42]. The relationship between sleep duration and stroke incidence is U-shaped in general; the risk for stroke is elevated in both short and long sleep groups [4345]. Short sleep, commonly defined as $<5$ to 6 hours of nocturnal sleep, increases the risks of stroke, coronary heart disease, and death $[44,46]$. Sleep deprivation leads to increased levels of the appetite stimulating hormone ghrelin and reduced levels of the anti-appetite hormone leptin [47]. Furthermore, reduced physical activity associated with sleep deprivation leads to weight gain by decreasing energy expenditure [48]. Short sleep is also associated with sympathetic overactivity, which leads to impaired glucose metabolism hypertension, and non-dipping of blood pressure [49-51]. Long sleep duration (more than 9 hours of sleep) is also associated with stroke and cardiovascular mortality [52]. The linking mechanisms between long sleep and stroke are still elusive, but increased inflammation and abnormal lipid profiles in long sleepers have recently been reported $[53,54]$.

Insomnia is prevalent in approximately $10 \%$ to $20 \%$ of the adult population, with approximately $50 \%$ having a chronic form. Chronic insomnia disorder is characterized by a complaint of difficulty initiating sleep and maintaining sleep and waking up earlier than desired. The diagnosis of chronic insomnia requires occurrences on at least three nights per week for at least 3 months. Insomnia was found to be a risk factor for cardiovascular events and death [55]. Elevated sympathetic and hypothalamic-pituitaryadrenal axis activity has been proposed as a mechanism for the cardiovascular effect of insomnia [8].

The defining feature of PLMS is periodic episodes of repetitive, highly stereotyped limb movements during sleep, which mostly occur in the lower extremities and can be associated with cortical arousal. A positive relationship between PLM and cardiovascular events or mortality has been demonstrated in observational studies, and a greater risk attributed to PLM combined with arousals [56,57]. PLM with arousal induces an abrupt increase in blood pressure and heart rate through sympathetic overshoot. Sympathetic overactivity, metabolic dysregulation, inflammation, oxidative stress, peripheral hypoxia, and hypothalamic pituitaryadrenal activation have been proposed as possible linking mechanisms between PLM/RLS (Restless leg syndrome) and cardiovascular diseases [58]. Repeated nocturnal fluctuations in heart rate and blood pressure that are associated with PLM and related microarousals cause daytime hypertension, subsequently increasing the risk for cerebrovascular diseases $[58,59]$.

\section{References}

1. Lozano R, Naghavi M, Foreman K, Lim S, Shibuya K, et al. (2012) Global and regional mortality from 235 causes of death for 20 age groups in 1990 and 2010: A systematic analysis for the global burden of disease study 2010. Lancet 380(9859): 2095-2128.

2. Feigin VL, Forouzanfar MH, Krishnamurthi R, Mensah GA, Connor M, et al. (2014) Global and regional burden of stroke during 1990-2010: Findings from the global burden of disease study 2010. Lancet 383(9913): $245-254$.

3. Koton S, Schneider AL, Rosamond WD, Shahar E, Sang Y, et al. (2014) Stroke incidence and mortality trends in US communities, 1987 to 2011. JAMA 312(3): 259-268.

4. Thrift AG, Howard G, Cadilhac DA, Howard VJ, Rothwell PM, et al. (2017) Global stroke statistics: An update of mortality data from countries using a broad code of "cerebrovascular diseases". Int J Stroke 12(8): 796-801.

5. Feigin VL, Roth GA, Naghavi M, Parmar P, Krishnamurthi R, et al. (2016) Global burden of stroke and risk factors in 188 countries, during 19902013: A systematic analysis for the global burden of disease study 2013. Lancet Neurol 15: 913-924.

6. Donnell MJ, Xavier D, Liu L, Zhang H, Chin SL, et al. (2010) Risk factors for ischaemic and intracerebral haemorrhagic stroke in 22 countries (the INTERSTROKE study): A case-control study. Lancet 376(3735): 112-123.

7. Cappuccio FP, Cooper D, Elia L, Strazzullo P, Miller MA (2011) Sleep duration predicts cardiovascular outcomes: A systematic review and meta-analysis of prospective studies. Eur Heart J 32(12): 1484-1492.

8. Vgontzas AN, Mendoza J, Liao D, Bixler EO (2013) Insomnia with objective short sleep duration: the most biologically severe phenotype of the disorder. Sleep Med Rev 17(4): 241-254.

9. Anothaisintawee T, Reutrakul S, Van Cauter E, Thakkinstian A (2016) Sleep disturbances compared to traditional risk factors for diabetes development: Systematic review and meta-analysis. Sleep Med Rev 30: $11-24$.

10. Saper CB, Fuller PM (2017) Wake-sleep circuitry: an overview. Curr Opin Neurobiol 44: 186-192.

11. Verrier RL, Harper RM, Kryger MH, Roth T, Dement WC (2010) Principles and practice of sleep medicine. St. Louis, MO: Elsevier Saunders 2011. Cardiovascular physiology: Central and autonomic regulation, USA, pp. 215-225.

12. Brien E (2009) Dipping comes of age: the importance of nocturnal blood pressure. Hypertension 53(3): 446-447.

13. Javaheri S, Redline S (2012) Sleep, slow-wave sleep, and blood pressure. Curr Hypertens Rep 14(5): 442-448.

14. Mancia G (1993) Autonomic modulation of the cardiovascular system during sleep. N Engl J Med 328(5): 347-349.

15. Somers VK, Dyken ME, Mark AL, Abboud FM (1993) Sympathetic-nerve activity during sleep in normal subjects. N Engl J Med 328(5): 303-307.

16. Bouhanick B, Bongard V, Amar J, Bousquel S, Chamontin B (2008) Prognostic value of nocturnal blood pressure and reverse-dipping status on the occurrence of cardiovascular events in hypertensive diabetic patients. Diabetes Metab 34(6): 560-567.

17. Loredo JS, Nelesen R, Israel S, Dimsdale JE (2004) Sleep quality and blood pressure dipping in normal adults. Sleep 27(6): 1097-1103.

18. Routledge FS, Durdle JA, Dean CR (2007) Canadian hypertension society. night-time blood pressure patterns and target organ damage: A review. Can J Cardiol 23(2): 132-138. 
19. Hajjar I, Zhao P, Alsop D, Abduljalil A, Selim M, et al. (2010) Association of blood pressure elevation and nocturnal dipping with brain atrophy, perfusion and functional measures in stroke and non-stroke individuals. Am J Hypertens 23(1): 17-23.

20. Redline S, Foody J (2011) Sleep disturbances: time to join the top 10 potentially modifiable cardiovascular risk factors? Circulation 124(19): 2049-2051.

21. Young T, Palta M, Dempsey J, Skatrud J, Weber S, Badr S (1993) The occurrence of sleep-disordered breathing among middle-aged adults. $\mathrm{N}$ Engl J Med 328(17): 1230-1235.

22. Peppard PE, Young T, Barnet JH, Palta M, Hagen EW, et al. (2013) Increased prevalence of sleep- disordered breathing in adults. Am J Epidemiol 177(9): 1006-1014

23. Bassetti CL, Hermann DM (2011) Sleep and stroke. Handb Clin Neurol 99: 1051-1072.

24. Koo DL, Kim JY, Lim JS, Kwon HM, Nam H (2017) Cerebral microbleeds on MRI in patients with obstructive sleep apnea. J Clin Sleep Med 13(1): 65-72.

25. Song TJ, Park JH, Choi KH, Chang Y, Moon J, et al. (2017) Moderate-to-severe obstructive sleep apnea is associated with cerebral small vessel disease. Sleep Med 30: 36-42.

26. Yun $\mathrm{CH}$, Jung $\mathrm{KH}$, Chu K, Kim SH, Ji KH, et al. (2010) Increased circulating endothelial microparticles and carotid atherosclerosis in obstructive sleep apnea. J Clin Neurol 6(2): 89-98.

27. Kim J, Mohler ER, Keenan BT, Maislin D, Arnardottir ES, et al. (2017) Carotid artery wall thickness in obese and nonobese adults with obstructive sleep apnea before and following positive airway pressure treatment. Sleep 40(9).

28. Peppard PE, Young T, Palta M, Skatrud J (2000) Prospective study of the association between sleep- disordered breathing and hypertension. $\mathrm{N}$ Engl J Med 342(19): 1378-1384.

29. Becker HF, Jerrentrup A, Ploch T, Grote L, Penzel T, et al. (2003) Effect of nasal continuous positive airway pressure treatment on blood pressure in patients with obstructive sleep apnea. Circulation 107(1): 68-73.

30. García MA, Capote F, Rodríguez F, Lloberes P, Atauri MJ, et al. (2013) Effect of CPAP on blood pressure in patients with obstructive sleep apnea and resistant hypertension: the HIPARCO randomized clinical trial. JAMA 310(22): 2407-2415.

31. Reutrakul S, Mokhlesi B (2017) Obstructive sleep apnea and diabetes: a state-of-the-art review. Chest 152(5): 1070-1086.

32. Mehra R, Benjamin EJ, Shahar E, Gottlieb DJ, Nawabit R, et al. (2006) Association of nocturnal arrhythmias with sleep-disordered breathing: The sleep heart health study. Am J Respir Crit Care Med 173(8): 910-916.

33. Gami AS, Hodge DO, Herges RM, Olson EJ, Nykodym J, et al. (2007) Obstructive sleep apnea, obesity, and the risk of incident atrial fibrillation. ] Am Coll Cardiol 49(5): 565-571.

34. McNicholas WT (2009) Obstructive sleep apnea and inflammation. Prog Cardiovasc Dis 51(5): 392-399.

35. Thomopoulos C, Tsioufis C, Dimitriadis K, Tsiachris D, Tousoulis D, et al. (2009) Obstructive sleep apnoea syndrome is associated with enhanced sub-clinical inflammation and asymmetric dimethyl- arginine levels in hypertensives. J Hum Hypertens 23(1): 65-67.

36. Yue HJ, Mills PJ, Israel S, Loredo JS, Ziegler MG, et al. (2009) The roles of TNF-alpha and the soluble TNF receptor I on sleep architecture in OSA. Sleep Breath 13(3): 263-269.

37. Lurie A (2011) Endothelial dysfunction in adults with obstructive sleep apnea. Adv Cardiol 46: 139-170.
38. Wang J, Yu W, Gao M, Zhang F, Gu C, et al. (2015) Impact of obstructive sleep apnea syndrome on endothelial function, arterial stiffening, and serum inflammatory markers: an updated meta-analysis and metaregression of 18 studies. J Am Heart Assocm 4(11): e002454.

39. Wessendorf TE, Thilmann AF, Wang YM, Schreiber A, Konietzko N, et al. (2000) Fibrinogen levels and obstructive sleep apnea in ischemic stroke. Am J Respir Crit Care Med 162(6): 2039-2042.

40. Von Känel R, Dimsdale JE (2003) Hemostatic alterations in patients with obstructive sleep apnea and the implications for cardiovascular disease. Chest 124(5): 1956-1967.

41. Saygin M, Ozturk O, Ozguner MF, Akkaya A, Varol E (2016) Hematological parameters as predictors of cardiovascular disease in obstructive sleep apnea syndrome patients. Angiology 67(5): 461-470.

42. Dong JY, Zhang YH, Qin LQ (2013) Obstructive sleep apnea and cardiovascular risk: meta-analysis of prospective cohort studies. Atherosclerosis 229(2): 489-495.

43. Chen JC, Brunner RL, Ren H, Smoller S, Larson JC, et al. (2008) Sleep duration and risk of ischemic stroke in postmenopausal women. Stroke 39(12): 3185-3192

44. Helbig AK, Stöckl D, Heier M, Ladwig KH, Meisinger C (2015) Symptoms of insomnia and sleep duration and their association with incident strokes: findings from the population-based MONICA/KORA Augsburg Cohort Study. PLoS One 10(7): e0134480.

45. Li W, Wang D, Cao S, Yin X, Gong Y, et al. (2016) Sleep duration and risk of stroke events and stroke mortality: a systematic review and meta-analysis of prospective cohort studies. Int J Cardiol 223: 870-876.

46. He Q, Sun H, Wu X, Zhang P, Dai H, et al. (2017) Sleep duration and risk of stroke: A dose-response meta-analysis of prospective cohort studies. Sleep Med 32: 66-74.

47. Taheri S, Lin L, Austin D, Young T, Mignot E (2004) Short sleep duration is associated with reduced leptin, elevated ghrelin, and increased body mass index. PLoS Med 1(3): e62.

48. Schmid SM, Hallschmid M, Chara K, Wilms B, Benedict C, et al. (2009) Short-term sleep loss decreases physical activity under free-living conditions but does not increase food intake under time- deprived laboratory conditions in healthy men. Am J Clin Nutr 90(6): 1476-1482

49. Phua CS, Jayaram L, Wijeratne T (2017) Relationship between sleep duration and risk factors for stroke. Front Neurol 8: 392.

50. Ortiz M, Abundis E, Muñoz BR, González S (2000) Effect of sleep deprivation on insulin sensitivity and cortisol concentration in healthy subjects. Diabetes Nutr Metab 13(2): 80-83.

51. Covassin N, Bukartyk J, Sahakyan K, Svatikova A, Calvin A, et al. (2015) Experimental sleep restriction increases nocturnal blood pressure and attenuates blood pressure dipping in healthy individuals. J Am Coll Cardiol 65(10): A1352.

52. Kim Y, Wilkens LR, Schembre SM, Henderson BE, Kolonel LN, et al. (2013) Insufficient and excessive amounts of sleep increase the risk of premature death from cardiovascular and other diseases: the multiethnic cohort study. Prev Med 57(4): 377-385.

53. Zhan Y, Chen R, Yu J (2014) Sleep duration and abnormal serum lipids: The China health and nutrition survey. Sleep Med 15(7): 833-839.

54. Ewert HK, Ridker PM, Rifai N, Regan MM, Price NJ, et al. (2004) Effect of sleep loss on C-reactive protein, an inflammatory marker of cardiovascular risk. J Am Coll Cardiol 43(4): 678-683.

55. Chien KL, Chen PC, Hsu HC, Su TC, Sung FC, et al. (2010) Habitual sleep duration and insomnia and the risk of cardiovascular events and allcause death: report from a community-based cohort. Sleep 33(2): 177184 
56. Koo BB, Blackwell T, Israel S, Stone KL, Stefanick ML, et al. (2011) Association of incident cardiovascular disease with periodic limb movements during sleep in older men: Outcomes of sleep disorders in older men (MrOS) study. Circulation 124(11): 1223-1231.

57. Mirza M, Shen WK, Sofi A, Jahangir A, Mori N, et al. (2013) Frequent periodic leg movement during sleep is associated with left ventricular hypertrophy and adverse cardiovascular outcomes. J Am Soc Echocardiogr 26(7): 783-790.
58. Walters AS, Rye DB (2009) Review of the relationship of restless legs syndrome and periodic limb movements in sleep to hypertension, heart disease, and stroke. Sleep 32(5): 589-597.

59. Pennestri MH, Montplaisir J, Colombo R, Lavigne G, Lanfranchi PA (2007) Nocturnal blood pressure changes in patients with restless legs syndrome. Neurolo 68(15): 1213-1218.

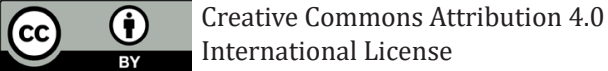

For possible submissions Click Here
Submit Article

\section{EPMR} Examines in
Physical Medicine
\& Rehabilitation

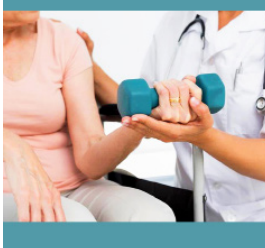

Examines in Physical Medicine and Rehabilitation Open Access

\section{Benefits of Publishing with us}

- High-level peer review and editorial services

- Freely accessible online immediately upon publication

- Authors retain the copyright to their work

- Licensing it under a Creative Commons license

- Visibility through different online platforms 